\title{
O FUTEBOL FEMININO NO DISCURSO TELEVISIVO
}

\author{
MS. DOIARA SILVA DOS SANTOS \\ Mestre em Educação Física pelo Centro de Educação Física e Desportos da Universidade Federal do \\ Espírito Santo (CEFD/NFES) (Vitória - Espírito Santo - Brasil) \\ E-mail: doiarasantos@yahoo.com.br \\ GRAD. ANA GABRIELA ALVES MEDEIROS \\ Mestranda em Educação Física pelo Centro de Educação Física e Desportos da Universidade Federal \\ do Espírito Santo (CEFD/NFES) (Vitória - Espírito Santo - Brasil) \\ E-mail: gabimedeirosef@gmail.com
}

\begin{abstract}
RESUMO
Este estudo teve por objetivo analisar as características discursivas da narração de partidas disputadas pela equipe do Santos Futebol Clube na Copa Libertadores de Futebol Feminino (CLF). Para tanto, foram gravadas, transcritas e analisadas (segundo a teoria da Análise Crítica do Discurso) as transmissões das partidas disputadas pela equipe. Percebemos que nas narrativas investigadas, sobressai o apelo estético em torno das mulheres, em detrimento aos aspectos técnicos e táticos da prática esportivo-competitiva em si. Por essa razão, os sentidos incorporados à prática profissional do futebol feminino continuam carecendo de uma ressignificação, como apontado por Goellner (2005). Entendemos que tal ressignificação perpassa todo o processo comunicativo.
\end{abstract}

PALAVRAS - CHAVE: Futebol; discurso; televisão; comunicação. 
As relações entre o esporte e os meios de comunicação expressam, reconhecidamente, relevante significado social (ELIAS; DUNNING, 1995). É fato que a popularização do esporte no mundo moderno culminou com o avanço e desenvolvimento das mídias. Diante disso, o esporte e os meios de comunicação se influenciaram (e se influenciam) mutuamente nas esferas econômica, social, política, etc. (BRIGGS; BURKE, 2004).

A espetacularização do esporte é, pois, um dos desdobramentos de sua popularização, ao passo que, impulsionado pela veiculação nos meios de comunicação, tornou-se um fenômeno de massas de grande dimensão simbólica, que suscita problematizações importantes no contexto acadêmico-científico.

O futebol é tema recorrente em análises históricas, sociológicas, antropológicas, etc. Quando se trata de futebol feminino (FF) no Brasil, no levantamento de um estado da arte, estudos apontam que há um "reclame" por atenção e apoio da sociedade - principalmente por meio da mídia -, por parte de atletas e outros atores sociais do esporte vinculados a essa prática.

Goellner (2005, p. 143) contribui para entender do que se trata esse "reclame", ao dispor sobre o contexto geral de "sombras" no qual o futebol feminino se encontra, reiterando que:

[...] há muito tempo que as mulheres protagonizam histórias no futebol brasileiro ainda que tenham pouca visibilidade, seja na mídia esportiva, no cotidiano dos clubes e associações esportivas, na educação física escolar ou nas políticas públicas de lazer.

Ao realizar a análise de fragmentos de mídia impressa de 1930 a 2000, Mourão e Morel (2005) constataram que não se trata apenas do futebol, mas que houve resistências para legitimar o esporte feminino como um todo na sociedade brasileira. Para as autoras, tais resistências se refletem no fato de que as transformações discursivas associadas ao tema são lentas e, especificamente no que concerne ao FF, não evoluem.

Martins e Moraes (2007, p. 80), por sua vez, apontam um "silêncio da mídia" quando o assunto é o futebol feminino, definindo tal desatenção como um "estado de dormência".

No entanto, no Brasil, alguns resultados obtidos pela seleção nacional de FF constituíram momentos de visibilidade como, por exemplo: a conquista da medalha de prata nos Jogos Olímpicos de Atenas em 2004; a conquista da medalha de ouro nos Jogos Pan-Americanos em 2007; o vice-campeonato mundial em 2007; e a conquista do título de melhor jogadora do mundo por Marta consecutivas vezes (em 2006, 2007, 2008 e 2009). 
Estes fatos foram, por vezes, propulsores para discursos em prol de um fortalecimento do FF em termos organizacionais, sobretudo, em relação à profissionalização das atletas (com a criação de um campeonato nacional de alto nível).

A questão que motiva este estudo diz respeito aos momentos de visibilidade do FF. Diante disso, o acontecimento inédito da Copa Santander Libertadores da América de Futebol Feminino (CLF) suscitou a questão: Como se caracterizam as narrações de partidas da equipe do Santos Futebol Clube na CLF pela Rede Bandeirantes? Em outras palavras, como o futebol feminino é significado no discurso midiático?

Pela dimensão internacional do evento, e a cobertura de uma transmissora de televisão a nível nacional, caracterizamos essa competição como um potencial momento de visibilidade do FF. Desse ponto de partida, objetivamos identificar e analisar as características que emolduram as narrações de partidas do Futebol Feminino, tomando como referência a equipe brasileira, o Santos. Para tanto, foram gravadas e transcritas as transmissões das partidas disputadas pela equipe.

O foco da análise são as narrações das partidas em si, mas outros aspectos da transmissão - como entrevistas e comentários pré e pós jogo - que pudessem complementar e elucidar a análise dos dados obtidos, não foram descartados.

A partir de uma abordagem qualitativa, numa perspectiva descritiva e interpretativa dos dados coletados (MARCONI; LAKATOS, 2007), a análise fundamenta-se na teoria da Análise Crítica do Discurso. O discurso aqui compreendido em três dimensões: texto, interação (prática discursiva) e contexto (prática social). Tais dimensões são simultâneas e se inter-relacionam.

Neste estudo foram enfatizadas as análises discursiva e social. A primeira trabalha com a natureza da produção e interpretação textual. A última analisa as circunstâncias institucionais e organizacionais do evento discursivo, e de que maneira elas moldam a natureza da prática discursiva (FAIRCLOUGH, 1992 apud GOMES, 2007, p. 16).

\section{O EVENTO DISCURSIVO: CONTEXTO E SIGNIFICAÇÕES SIMBÓLICAS}

De 3 a 18 de outubro de 2009 ocorreu a primeira edição da CLF. Todas as partidas da competição aconteceram no Brasil, com a cobertura e transmissão em nível nacional das partidas do Santos Futebol Clube (SFC) pela Rede Bandeirantes de televisão (canal aberto). $O$ ineditismo da competição foi marcado pela participação de jogadoras consagradas na seleção nacional, que foram contratadas pelo SFC especialmente para este evento: Marta e Cristiane.

Dez países da América do Sul tiveram equipes representativas no evento, que foram: San Lorenzo de Almagro (Argentina), Club Desportivo EnForma (Bolívia), 
Santos Futebol Clube (Brasil), Club Everton (Chile), Club Desportivo Formas Íntimas (Colômbia), Sociedad Desportivo Quito (Equador), Universidad Autónoma de Assunción (Paraguai), Club White Star (Peru), Rampla Juniors Futbol Club (Uruguai) e Caracas Futebol Club (Venezuela). A equipe do Santos sagrou-se campeã invicta da competição na final contra a equipe da Universidad Autonoma e garantiu, assim, a participação no primeiro Mundial de Clubes Feminino.

Diferentemente do futebol masculino, o futebol feminino no Brasil não foi, primeiramente, uma prática esportiva elitizada. As considerações de Goellner (2005, p. I 45) sobre a prática esportiva para as mulheres ilustram, historicamente, razões que podem explicar esse fato:

[...] o temor à desmoralização feminina frente à exibição e espetacularização do corpo se traduzia num fantasma a rondar as famílias, em especial, as da elite. A prática esportiva, o cuidado com a aparência, o desnudamento do corpo e o uso de artifícios estéticos, por exemplo, eram identificados como impulsionadores da modernização da mulher e da sua auto-afirmação na sociedade e, pelo seu contrário, como de natureza vulgar que a aproximava do universo da desonra e da prostituição.

Embora diversas transformações e avanços tenham ocorrido ao longo do século $X X$ e $X X I$, ainda é considerada precária a estruturação do FF no Brasil. Os campeonatos são escassos, o processo de profissionalização das atletas é lento. As políticas privadas e públicas direcionadas para o incentivo às meninas e mulheres que desejam praticar esse esporte, no nível competitivo ou não, são efêmeras (GOELLNER, 2005).

Consequentemente, no que concerne à mídia esportiva, são também efêmeros os espaços conferidos às competições de futebol feminino no nível nacional e/ou internacional. Quando alguma atenção é dada a essa prática, geralmente, não só os talentos esportivos das atletas, árbitras ou treinadoras, mas a sua imagem (estética) e o seu comportamento são observados (MARTINS; MORAES, 2007).

Essa dimensão do discurso midiático em torno do FF também foi verificada nesta investigação. Na partida entre Santos e EnForma, a segunda da fase classificatória, o narrador Luciano do Valle (LV) e o comentarista Osmar de Oliveira (OS), em seus discursos, tornam a dimensão estética evidenciada:

LV: “[...] Olha lá, partiu... jogada ensaiada, bela defesa da goleira boliviana Lizeth Velasco. Ela é fortinha em?"

OS: "Aliás, todo o time aí está precisando de um regime."

LV: "Santa Cruz de La Sierra tem grandes restaurantes viu? É diferente de La Paz. (Risos)" 
Em meio à narração da jogada, narrador e comentarista destinam seus comentários, primeiramente, à condição física (aparência) da atleta boliviana Lizeth Velasco. Posteriormente, esse comentário se estende a outras jogadoras da equipe. Possíveis elementos técnicos e táticos da jogada, que tinha acabado de acontecer, não foram mencionados.

O discurso de OS tem caráter prescritivo e negligencia qualquer fundamentação em dados e informações da comissão técnica da equipe. LV, por sua vez, ironiza e especula sobre a condição física das atletas, mencionando a qualidade, de acordo com seu julgamento, dos restaurantes da região que a equipe representa.

Notamos que a dimensão estética assume desdobramentos distintos. No trecho abaixo o uso de acessórios é notado:

LV: "[...] Olha o Brasil, mais uma vez, liberdade, precisa ver se a goleira chega primeiro, chegou! Boa saída da Lizeth Velascos, jogando com seu bonezinho. 'Tá' certo que o sol não apareceu, mas, ela botou o boné acho que pra mais arrumar o rabinho de cavalo. São detalhes que o futebol feminino podem [sic] apresentar para o locutor. Se bem que houve uma época que teve muito argentino com o cabelo assim jogando."

O narrador avaliou tecnicamente o envolvimento da goleira boliviana na jogada e, em seguida, reconhece, na dimensão estética, detalhes que o FF tem a oferecer. As jogadoras brasileiras também foram alvo de observações nesse sentido, como observado a seguir:

LV: “[...] Mas 'ó' quem 'tá lá... ó' quem vai tentar buscar, correu, bola fora! 'Tá' voltando ali a Marta. O cabelo da Marta 'tá' bem arrumado 'né'? [...]”

LV: “[...] Pega mal na bola a Dani, 'tá' retornando a Dani com o seu cabelo solto.”

A teoria configuracional desenvolvida por Elias e Dunning ( 1995) pode ajudar a compreender as razões pelas quais houve esse deslocamento para a dimensão estética nas narrações analisadas. Elias e Dunning (1995) localizam o esporte no contexto de um amplo e longo processo civilizador, como um confronto mimético, no qual o ser humano busca emoções controladas, busca excitação.

No entanto, se por algum motivo o esporte ou a atividade de lazer perde a capacidade de provocar essa excitação, elas podem perder a função de fornecer um grau de insegurança, de satisfazer a expectativa das pessoas por algo inesperado, e o risco, a tensão e ansiedade que o acompanha.

Nesse sentido, percebemos que a diferença qualitativa da equipe do SFC em relação às outras equipes que disputaram a CLF (ilustradas pelos placares elásticos)'

I. Por exemplo: Santos $12 \times 0$ EnForma e Santos $9 \times 0$ Universidade Autônoma de Assunção. 
descentralizou a cobertura de seus aspectos técnicos e táticos (que não deixaram de existir).

Percebemos que narradores, comentaristas e repórteres, como agentes de um veículo midiático, que precisam manter o interesse do público (neste caso o telespectador), deslocaram a atenção do mesmo para outros aspectos do evento, pela ausência de elementos que pudessem trazer a emoção e tensão buscadas no esporte. Durante as transmissões, explorou-se outra dimensão do entretenimento: a curiosidade, o "extra" ordinário.

No fragmento a seguir, em interação com a repórter Fabíola Andrade (FA), Luciano do Vale explicita os elementos explorados por ele durante a transmissão, como se verifica a seguir:

LV: "[...] Fabíola Andrade, a mulher sempre tem algumas coisas interessantes para serem acrescentadas numa transmissão, por isso que eu acho que o nosso sexo oposto, que na verdade é o sexo... não é oposto, é que nos ajuda muito, é companheirão...você pode trazer algumas novidades das meninas? Qual é... O time da Bolívia é um time de bonitas? É um time de cabelo arrumado? Elas são vaidosas? Como é que é esse EnForme [sic] aí Fabíola?"

FA: 'Luciano, nesse quesito eu acho que as brasileiras 'tão' mais bonitas, mais bem arrumadas, a brasileira é muito vaidosa 'né'? Não que as bolivianas não venham também para campo bem cuidadas, mas, é... as brasileiras parece que cuidam mais dessa parte do visual do que as bolivianas...elas apesar de não terem dado nem um chute a gol ainda, parece que elas são mais focadas no futebol, mas a beleza brasileira também se revela nas jogadas da Cristiane e da Marta 'né'?"

O comportamento das atletas também é analisado por LV e OS:

LV: “[...] Mas eu volto insistir a Marta 'tá' diferente hoje, em? Há uma mutação até no futebol 'né'? Diz que a mulher tem uma bipolaridade impressionante, Doutor.... Eu 'tô' falando porque eu to com um Doutor aqui do lado, por isso que eu 'tô' falando!"

OS: "Em todos os sentidos! Elas são mais sensíveis, são mais volúveis, tem mais coração não é? Mas, quando dá a bipolaridade do outro lado, sai de baixo!"

LV busca legitimar seu comentário ao respaldar-se na presença de Osmar de Oliveira, que tem formação em Medicina pela Faculdade de Medicina da Pontifícia Universidade Católica (1969), Sorocaba - SP, e é especialista em Medicina esportiva. $\bigcirc$ assunto se prolonga e abrange outros integrantes da transmissão, como a repórter Fabíola Andrade. 
LV: “[...] A Marta 'tá' desanimada, com a cabeça pra baixo... Já, já acerta uma jogada [...]”

FA: "E a Cristiane, Luciano, ao contrário da Marta, é só sorrisos aqui. Ela que [...] é artilheira da competição 'tá' rindo à toa no gramado."

OS: "Fabíola do céu, a mulher tem uma coisa chamada estrógeno, uma coisa chamada progesterona que os homens não tem [...]"

FA: "Doutor Osmar, vocês já falaram da bipolaridade... Estou só ouvindo aqui, eu estou ouvindo tudo, você e o Luciano 'aí'."

OS: "Não, mas é justamente o estrógeno e a progesterona que pode dar essas mudanças de comportamento, mas não tira da mulher a afetividade, o carinho, a doçura, a pele melhor do que os homens, tudo isso... Inclusive uma artilheira que poucos homens do Brasil faz um gol do jeito que a Cristiane fez."

LV: "É verdade. Beleza Osmar, beleza!"

O evento foi codificado a partir dos referenciais de sentido dos envolvidos na transmissão que, ao vivo, divergem durante o próprio processo de codificação do evento, como fica evidenciado no comentário de Luciano de Valle sobre a repórter Fabíola Andrade:

LV: "Fim de jogo [...] Fabíola Andrade está preocupada com os comentários, daqui a pouco ela sai em defesa da mulher, vamos lá!"

A repórter Fabíola Andrade se posiciona em relação a este apelo à estética de forma resistente, como se verifica em sua interação com LV:

LV: “[...] $\bigcirc$ Neto elogiou o rosto dessa menina como um dos mais bonitos do time. Até fizemos uma votação [...] hoje vou aproveitar pra fazer no finzinho do jogo. Você pense direitinho, o rosto da Érika que acabou de deixar o gramado. E, aliás, a mulher sempre tem uma sensibilidade melhor para falar disso, porque concurso de beleza, essas coisas olha... Você concorda com isso Fabíola? É o rosto mais assim ajeitadinho, o narizinho, tudo mais ou não?"

FA: "É muito bonita mesmo, agora tem gosto para tudo também 'né'?"

O narrador, o comentarista e o repórter Evaldo Marcos (EV) fizeram uso de outra estratégia para entreter e chamar a atenção do público, já que torcer pela 
vitória do SFC, que aos quinze minutos do segundo tempo ganhava de 7 a 0 e dominava a partida contra o EnForma, não era razão para continuar assistindo ao jogo, como pode-se observar nos fragmentos abaixo:

OS: "[...] Não precisa nem falar, o telespectador está vendo... O time brasileiro sobra taticamente, tecnicamente, físicamente... e eu acho que a gente vai chegar a doze."

EV: "[...] É que a zagueira ficou dando uma enroladinha pra bater lá a bola parada, querendo ganhar tempo 'né' Luciano. Não quer os dois dígitos não."

LV: "[...] Todo mundo quer, o Brasil inteiro quer [...] Agora nós vamos jogar contra o relógio, para fazer os dois dígitos 'né'? Sete a zero! E é a primeira Copa Libertadores, oficial da FIFA, COMEBOL! É um resultado que passará para a história mesmo do futebol feminino, que está cada vez mais crescendo em todo o mundo."

estabelecimento de novas metas, novos motivos para continuar assistindo ao jogo, parece ter sido outra maneira encontrada para manter o interesse do telespectador. Vale ressaltar, porém, que a maioria do público presente no estádio não tinha a mediação da equipe de transmissão da Rede Bandeirantes para deslocar seu interesse a um ou outro aspecto da partida. Somente um estudo etnográfico poderia fornecer elementos indicadores sobre as reações e atitudes do público naquele contexto.

Outra dimensão verificada na análise das narrativas é a comparação com o futebol masculino, enfatizada em diversos momentos durante a partida entre a equipe do Santos e Formas Íntimas, seja em seus recursos técnicos e/ou táticos:

EV: "[...] o futebol feminino está tão fantástico. É tudo igual ao futebol masculino, aquela "catimba", aquela conversa antes, aquele pessoal que fica agitando, é tudo igual."

LV: "É tudo igual e com detalhe, você vendo daqui de cima... a gente está vendo daqui a disposição tática...é uma coisa...três de frente, o meio campo...então, é uma coisa maravilhosa."

OS: “[...] Luciano, numa grande época do Santos, o melhor time do mundo talvez, um dos melhores que eu já vi jogar, o Santos impressionou o mundo no futebol masculino com a dupla de ataque de Coutinho e Pelé, um pouco antes disso, Pagão e Pelé, "né"? E é o que a gente está vendo agora no próprio Santos com a Marta e a Cristiane."

LV: "E o Pagão poderia ser colocado como a Érika que é a terceira jogadora."

OS: "Perfeitamente." 
Através das falas dos envolvidos na transmissão, torna-se perceptível que a comparação traz intrínseca uma igualdade conquistada pelas mulheres nos gramados, as quais, ao entrar nos campos, estabeleceram momentos de rara igualdade de papéis, proporcionados pela técnica e pela tática, porquanto, esses fatores independem de sexo (FURLAN; SANTOS, 2008).

Entretanto, DaMatta (2003) alega que no Brasil, embora haja progressos e variações locais e regionais, é inadequado afirmar que o futebol é um esporte praticado indiferentemente por homens e mulheres. Neste contexto, uma das diferenças que podemos apontar pode ser observada nos fragmentos a seguir:

OS: "[...] Você já imaginou se o futebol feminino continuar com esse crescimento? A gente ter uma final de campeonato brasileiro Corinthians e Flamengo no Maracanã, com 50.000 pessoas? Aí os dirigentes falam: Ah! É coisa muito cara. Mas eu vou dizer o seguinte, em cada time grande do futebol brasileiro tem um caneludo que, às vezes, não vai nem para o banco e ganha mais de $\mathrm{R} \$ \mathbf{1 0 0 . 0 0 0 , 0 0}$ (cem mil reais) por mês. Com esse dinheiro mantém um time feminino."

LV: "E bom!"

OS: "É um cabeludo pelas sereias. E olhe que é uma troca fantástica."

Desta forma, podemos verificar, durante a narração, que há uma supervalorização do mercado futebolístico masculino, e subvalorização do feminino, em que o mesmo se torna atrativo por aspectos que ultrapassam a prática esportiva-competitiva em si.

\section{CONSIDERAÇÕES FINAIS: POR UMA RESSIGNIFICAÇÃO}

Percebemos que, neste momento de visibilidade do FF, houve um processo de deslocamento na transmissão televisiva (a partir de seu narrador e comentaristas), dos aspectos técnicos e táticos do jogo, para a ênfase na dimensão estética. Entendemos que, nas partidas analisadas, a disparidade no nível técnico entre a equipe brasileira e a equipe colombiana contribuiu para esse deslocamento.

Goellner (2005, p. 148) constatou que, no discurso sobre o esporte feminino, predomina uma "representação essencialista de gênero". Segundo a autora,

A espetacularização do corpo feminino é aceita e incentivada em determinados locais sociais, em especial, aqueles que valorizam uma representação de feminilidade construída e ancorada na exacerbação, por exemplo, da beleza e da sensualidade. Noutros, como o campo de futebol ou as arenas de lutas, essa espetacularização direciona-se para o 
estranhamento a estes corpos femininos performantes, fundamentalmente, porque às mulheres, cuja aparência corporal é excessivamente transformada pelo exercício físico e pelo treinamento contínuo, são atribuídas características viris que não apenas questionam sua feminilidade, mas também colocam em dúvida a autenticidade do seu sexo.

No entanto, na narrativa analisada por este estudo, esse estranhamento não esteve em evidência. Por outro lado, houve constantes observações sobre a beleza das atletas, sobretudo no que se refere aos acessórios, rostos, pernas, cabelos, unhas, e também comportamento. De certa forma, a observância desses elementos destacou a feminilidade de algumas atletas, sem, por outro lado, questioná-las em outras.

Encontramos no apelo estético da transmissão uma característica que pode estar presente em outros momentos do processo comunicativo, e não somente no evento codificado (ou seja, na narrativa). Não obstante, a compreensão de processo comunicativo, como desenvolvida por Hall (2003), sugere que o que a mídia capta já é um universo discursivo.

Nesse sentido, Goellner (2005, p. I 50) chama a atenção:

[...] em se tratando de um país como o Brasil, onde o futebol é discursivamente incorporado à identidade nacional, torna-se necessário pensar, o quanto este ainda é, para as mulheres, um espaço não apenas a conquistar, mas, sobretudo, a ressignificar alguns dos sentidos que a ele estão incorporados [..]

Há de se considerar que a decodificação das mensagens depende dos referenciais de sentido do "consumidor" destas mensagens, os quais podem convergir ou divergir dos referenciais utilizados para a codificação (HALL, 2003). $\bigcirc$ "consumidor" pode perceber o "sentido preferencial" que a emissora de televisão (neste caso) atribui e, ao mesmo tempo, ter outras possibilidades interpretativas, ou não.

Assim, é preciso atentar para o fato de que a ressignificação das narrativas do futebol feminino não deve se restringir aos meios de comunicação. Perpassa diferentes instâncias sócio-políticas e culturais para as quais ações peculiares devem ser mobilizadas. Conhecer o processo de codificação e as possibilidades interpretativas que ele suscita, permite tornar a possibilidade de investigação do processo de decodificação menos rígida, evitando incorrer no equívoco de considerar tal processo "mais" relevante para a análise sociológica, portanto, admitindo uma relação causal no processo comunicativo que o desconstruiria como um processo não-linear.

\section{Female Soccer in the televise discourse}

ABSTRACT: This study aimed to analyze the discursive features of soccer matches narratives played by the Santos Futebol Clube team in the Copa Libertadores de Futebol Feminino (CLF). 
For this, the matches played by the team were recorded, transcript and analyzed (based in the theory of Critical Discursive Analysis). We realized that in the investigated narratives, it comes up the aesthetic appeal instead of the sportive-competitive practice itself. For this reason, the meanings embedded in these discourses are still lacking a new meaning as appointed by Goellner (2005). It is our understanding that it encompasses the whole communicative process. KEYWORDS: Soccer; discurse; televisio; communication.

\section{Fútbol femenino en el discurso televisivo}

RESUMÉN: Este estudio tuvo como objetivo examinar las características discursivas de la narración de partidos jugados por el equipo de Santos Futebol Clube en la Copa Libertadores de fútbol femenino (CLF). Fueron grabadas, transcritas y analizadas ( con base en la teoría del Análisis Crítico del Discurso) las transmisiones de partidos jugados por el equipo. Nos damos cuenta de que en los relatos estudiados, se destaca la estética en vez de la práctica desportiva con sentido competitivo en sí. Por esto, los significados incorporados en estos discursos siguen faltando una reinterpretación. Comprendemos que esto permea todo el proceso de comunicación.

PALABRAS CLAVE: Fútbol; discurso; television; comunicación.

\section{REFERÊNCIAS}

BRIGGS, A; BURKE, P. Uma história social da mídia: de Gutenberg à internet. Tradução Maria Carmelita Pádua Dias. Rio de Janeiro: Jorge Zahar, 2004.

DAMATTA, R. Em Torno da dialética entre igualdade e hierarquia: notas sobre as imagens e representações dos jogos olímpicos e do futebol no Brasil. Antropolítica, Rio de Janeiro, v. I, n. 14, p. 17-39, jan./jun. 2003.

ELIAS, N; DUNNING, E. A busca pela excitação. Lisboa: Difel, 1995.

FURLAN, C. C.; DOS SANTOS, P. L. Futebol feminino e as barreiras do sexismo nas escolas: reflexões acerca da invisibilidade. Motrivivência, Florianópolis, ano 20, n. 30, p. 28-43, jun. 2008.

GOELLNER, S. V. Mulheres e futebol no Brasil: entre sombras e visibilidades. Revista Brasileira de Educação Física e Esporte, São Paulo, v. 19, n. 2, p. |43-5 I, abr.jun. 2005.

GOMES, M. C. A. Considerações sobre os estudos discursivos críticos: o projeto social discursivo de Norman Fairclough. In:

; MELO, M. S. S.; CATALDI, C. Gênero discursivo, mídia e identidade. Viçosa: Ed. da UFV, 2007.

HALL, S. Da diáspora: identidade e mediações culturais. Belo Horizonte: Ed. da UFMG, 2003.

MARCONI, M. A.; LAKATOS, E. M. Técnicas de pesquisa: planejamento e execução de pesquisas, amostragens e técnicas de pesquisas, elaboração, análise e interpretação de dados. 6. ed. São Paulo: Atlas, 2007. 
MARTINS, L. T.; MORAES, L. Futebol feminino e sua inserção na mídia: a diferença que faz uma medalha de prata. Pensar a Prática, Goiânia, v. I, n. 10, p. 69-8I, jan./jun. 2007.

MOURÃO, L.; MOREL, M. As narrativas sobre o futebol feminino: o discurso da mídia impressa em campo. Revista Brasileira de Ciências do Esporte, Campinas, v. 26, p. 73-86, 2005.

Recebido:30 set 2010 Aprovado:25 mai 201 I

Endereço para correspondência: Doiara Silva dos Santos Universidade Federal do Espírito Santo Centro de Educação Física e Desportos Av. Fernando Ferrari, 5I4 Campus de Goiabeiras, Vitória-ES CEP 29075-910 